\title{
It is not just about the Technology: A Large Scale Implementation of Moodle as a VLE across Schools in South Wales
}

\author{
Catherine Naamani \\ University of Glamorgan, United Kingdom
}

\begin{abstract}
In 2009, Rhondda-Cynon-Taff Local Authority in South Wales took a strategic decision to adopt Moodle as the Virtual Learning Environment for all its schools. This paper explores how the project has evolved and how Moodle is being used in schools at the present time. It describes some of the ways in which Moodle is being used in different schools in both secondary and primary sectors. The paper reviews a variety of adoption models and explores how different approaches to change have impacted upon the project, and suggests that there is a clear relationship between effective leadership in a school and the successful adoption of Moodle. The paper concludes with a summary of areas for further discussion and research.
\end{abstract}

\section{Introduction}

The role of technology in enhancing learning and teaching in schools has been a priority both in England and in the devolved administrations in Scotland, Northern Ireland and Wales for over a decade. In the second half of the 2000s, thinking began to include the promotion of Virtual Learning Environments (VLEs) or Learning Platforms as a key driver towards improving education and skills. In England, through its e-Strategy, 'Harnessing Technology: Transforming learning and children's services', the focus of the then Department for Education and Skills was very much on providing online support to learners, parents and teachers [2]; in Northern Ireland the Classroom 2000 (C2k) initiative and Learning NI have been at the heart of the Department of Education's vision to enhance learning, teaching and leadership through educational technology since 2003 [3] and in 2007 Scotland launched its 'Glow' project, 'the world's first national intranet for education' [4]. In Wales, too, significant emphasis was being placed on the role of technology in education and the need to improve ICT skills and in 2008, the Schools ICT Strategy Working Group published its report on transforming schools with ICT [15]. The report included in its recommendations the establishment of 'bilingual learning platforms across Wales' [15]. More recently, in 2010, the Welsh Government published its ICT framework, 'Delivering a Digital Wales', which includes the development of 'a nationally coordinated approach to the use of Learning Platforms' [16] as one of its aims. This was followed by the publication, in March 2012, of a report on the review of the use of technology to support learning and teaching in the classroom, 'Find it, Make it, Use it, Share it: learning in digital Wales' [18]. The report includes in its recommendations the imperative to embed the use of digital technology in education which, in combination with sound pedagogy it is suggested, 'have the potential to make a substantial difference to the quality of learning and to the overall performance of learning providers' $[18$, p2]. A key outcome of the review is the development of a cross Wales Learning Platform, 'Hwb', to be launched in December 2012.

This paper aims to explore the impact of a strategy adopted by one Local Authority in South Wales, to develop and promote the use of a Virtual Learning Environment in all schools as a response to government drivers. The paper reviews a variety of adoption models and explores how different approaches to change have impacted upon the project. It also identifies examples of good practice in the adoption and use of VLEs and suggests areas for further research and analysis.

\section{The Literature}

Reports published by the Northern Ireland Education \& Training Inspectorate in 2008 and by Ofsted in 2009 both make sober reading for anyone seeking evidence that Virtual Learning Environments have the potential to improve education and skills as had been anticipated in the early 2000s. The evaluation of learning environments undertaken in Northern Ireland [11, p9] reports that:

'While significant progress has been made in recent years with regard to the adoption of learning environments in a minority of schools, 
for the vast majority they remain underdeveloped and underused as a resource for teaching and learning'

Similar conclusions were reached by Ofsted [12, p4] who report that:

'We found that the exploitation of VLEs at curriculum level resembled more of a cottage industry than a national technological revolution. In most cases, at subject level, the VLE remained one small aspect of learning, supported by enthusiastic staff and learners.'

Interestingly, both reports indicate that uptake and usage are less prominent in primary schools than in secondary schools, a fact which as we will see, is not the case currently within Rhondda-Cynon-Taff.

Research [6, 9] into the implementation of technology suggests that the Northern Ireland and English experience is not dissimilar to examples elsewhere of the challenges associated with embedding the use of technology in educational settings.

Moore's technology adoption curve which takes us from the concept of the innovator, to early adopter, then early and late majority and finally to Traditionalist is well documented in the research literature [7, 9]. However, it is also reported that in educational contexts is frequently slower and more sporadic than in other sectors [5, 6, 9] Means [9] describes this as a paradox where we find ourselves in a situation where outside the classroom, teachers' and students' lives are increasingly dominated by technology, while in the classroom '...practice in most schools has changed little from that of the mid$20^{\text {th }}$ century' [9, p285]. This challenge is also reflected by Hall [6] who reports on the traditional reluctance of educators to adopt technology innovations in a society where there is a gap between what students use technology for in the classroom (printing documents) and how they use it outside the classroom (social networking and texting for example) Ertmer \& Ottenbreit-Leftwich [5] make the point that while in most professional settings, technology use is expected and forms part of the norm, in education this is not the case, reaffirming Means reflection that teachers use the same tools now as their predecessors.

Moore's technology adoption curve is however, only one model explaining how quickly and effectively the use of technology is implemented in an educational setting. Martin et al [8, p229] debate '...the factors that are likely to help or hinder the adoption, diffusion and exploitation of e-learning', suggesting that what they describe as an organisation's absorptive capacity impacts on how quickly an innovation is implemented. The adoption model they present has four stages and moves from
Acquisition (the extent to which an organization is to find out about a given innovation) > Assimilation (the extent to which an organization is able to understand the information gained during the acquisition stage) > Transformation (the extent to which an organization is able to integrate old knowledge with new knowledge) $>$ Exploitation (the extent to which an organization is able to use new knowledge to build on existing knowledge to produce system and sustained knowledge use). They go on to reflect that it is not just about organizational capacity to adopt change, but that learners' willingness to use technology also has a part to play. They place learners into five categories, explorers, pioneers, skeptics, paranoids and laggards, closely reflecting the stages in Moore's adoption model, and Rogers [in 6, p232] 'Diffusion of Innovation Model' which suggests that innovations are not adopted at the same time by everyone or as Hall goes on to say: 'Some are quick to try the new way, whereas others deliberately delay' [6, p232]. Hall goes on to contest that the implementation of innovation should not be thought of in terms of adoption, but rather a process. His Concerns Based Adoption Model (CBAM) [in Hall \& Hord, 6] is directly concerned with the introduction of technology innovations in schoolbased environments. He argues convincingly that

'Rather than assuming use if dichotomous (use/nonuse), in this perspective, becoming a competent and confident innovation user is a developmental phenomenon that takes time' [6, p234]

describing the challenge associated with innovation change more as a potentially long and deep chasm $[6, \mathrm{p} 234]$ than a smooth curve, an image that will ring true to many involved in promoting and improving the use of technology to enhance learning and teaching.

Other key factors highlighted in the literature that impact on how quickly or effectively technology innovation is implemented in an educational setting relates to school culture, leadership and change management. Ertmer \& Ottenbreit-Leftwich [5] suggest that culture is a key variable which influences teachers' beliefs. This of course, is in turn influenced by the Headteacher and his or her vision for the school. Reporting on a study of three schools by Somekh [2008, in 5], Ertmer \& OttenbreitLeftwich note that innovation happened on a schoolwide scale supported by the principal's vision and motivation. Hall [6] comes to a similar conclusion suggesting that leadership style is the most significant factor in achieving successful implementation of technology innovation. He places leaders into three main categories; Initiators who have clear, long-term goals and policies, Managers, who focus on rules and controlling resources and 
Responders, who allow others to lead on change. Unsurprisingly perhaps, it is the Initiators and Managers who experience greater success with implementing technology innovation. Luckin et al [7, p321] even suggest that '...the major obstacle to elearning was disinterest bordering on hostility from some of the senior management team' in reflection on their experience of embedding e-learning in one higher education setting.

The need for staff development and for an appropriate amount of time devoted to this is also identified as a key factor in successful implementation of technology innovation. This takes the form both of developing skills and more importantly changing pedagogical practice $[5,6,13]$ :

\begin{abstract}
'However, knowing how to use technology hardware (e.g., digital camera, science probe) and software (e.g., presentation tool, social networking site) is not enough to enable teachers to use the technology effectively in the classroom [...] But knowing how to use the tools is only the foundation. Teaching with technology requires teachers to expand their knowledge of pedagogical practices across multiple aspects of planning, implementation, and evaluation processes' [5, p 260]
\end{abstract}

\section{The Project}

In January 2009, Rhondda-Cynon-Taff Local Authority in South Wales embarked on an ambitious project to roll out Moodle as its chosen VLE to over 120 schools, including primaries, secondaries, Special schools and Pupil Referral Units. Prior to this, the Local Authority had supported a number of initiatives using a variety of different VLEs, including Microsoft Learning Gateway, Blackboard and SimplyClick. Some schools were already running their own Moodle.

The choice of Moodle was based on a number of factors, most notably:

Cost: Moodle is an open-source product and as such, there were no associated licensing costs. It was recognised however, that some investment would be needed to develop, maintain and run the Moodle environment. Previous VLE projects had also identified the need for building in time and resource for effective staff development.

Flexibility: Moodle was felt to be one of the most flexible VLEs available, thus suitable for a range of different learners, ages and needs. Moodle was also customizable so schools would be able to choose their own look and feel. The fact that there were no licensing costs also provided greater flexibility in terms of user access.
Ease of use: The Local Authority had as we have reported, already had experience of using a variety of VLEs and it was agreed that Moodle appeared to be the most user-friendly.

Ability to share: At the time of the start of the project, Moodle was widely used across the Further Education sector in Wales and increasingly in the schools sector. At the same time, a number of key drivers and initiatives from the Department for Education and Skills in the Welsh Government focused on promoting collaboration at a number of levels; these included the Community Focused Schools initiative, which encouraged schools to build closer links with their local community [10]; 14-19 Learning Pathways which set out to promote more flexible curriculum delivery with greater collaboration between schools, colleges and workbased learning providers [17]; the School Effectiveness Framework which seeks to establish increased partnership working within and between schools to disseminate and enhance good practice through the development of Professional Learning Communities [14]; and more latterly, the development of regional consortia based working. Moodle, it was felt, was an ideal tool to facilitate collaborative activity, thereby supporting the work of the Local Authority and schools in achieving many of the aims set out by the Welsh Government.

\subsection{Project Implementation}

The first stage of the project anticipated setting up a pilot Moodle environment to be hosted within the Local Authority Wider Area Network (WAN) and supported by the Local Authority Corporate ICT department (CICT). A small number of schools, identified because of their previous experience, ICT readiness and interest in the project, were invited to test the environment. Lack of resource and expertise within CICT however, meant that the pilot was of limited success and it quickly became evident that such a model was not scalable. The University of Glamorgan, which has its main campus in RhonddaCynon-Taff and which had existing partnership arrangements with the Local Authority, was consequently approached and following agreement on a Memorandum of Understanding, it was confirmed that the University would host a Moodle environment for the Local Authority. This would have the additional benefit of technical support provided by a wider team with extensive experience of supporting both Moodle and Blackboard. Furthermore, staff development would be provided by the University's Centre for Excellence in Learning and Teaching (CELT), who had expertise in developing a strategy to promote the use of VLEs and of providing staff development in this area. Two members of staff from the department (a project 
manager and a staff development officer) were therefore seconded to the Local Authority to manage and support the project.

In the first year of the project, Welsh Government grant funding was identified to support the pilot. Schools were invited to submit an expression of interest, signed off by the Headteacher, outlining how they would use Moodle and how the school would support and sustain it. Based on previous VLE experience, the strategy adopted by the Local Authority was to ensure that the project would not be limited to simply providing a VLE and infrastructure, but made certain that schools would be fully supported to implement it both from a technical perspective and more significantly,in terms of providing appropriate staff development, led by CELT working with school-based Moodle champions and teams which included both teaching and support staff. Schools were encouraged to outline how they would evaluate and disseminate the project and how they would link their proposed use of Moodle to the Becta Self-Review Framework [1], which was being promoted as a vehicle to assess and improve the use of ICT in schools.

In spite of some initial resistance, approximately 40 schools signed up for the project in January 2009. From 2010/11, in order to develop greater sustainability, schools were asked to pay a charge for their Moodle instance, on a sliding scale based on school size. All but 2 of the original 40 schools opted to remain with the project and a further 20 signed up. In March 2012, the Local Authority took a strategic decision to use Moodle as the main electronic means of communication with schools and by September 2012, there were just over 95 schools involved, with another 6 Moodle environments aimed at supporting a range of Local Authority services.

\subsection{Support Model}

The support model that was adopted took into account technical support needs, individual school needs, and staff development needs and the following approach was adopted:

- Following receipt of the expression of interest, an initial meeting was set up between the project manager, the staff development officer and the Headteacher of the school concerned. The aim of the meeting was to establish the school's needs, understanding of Moodle and its potential as a tool to enhance learning and teaching. Discussions also took place around the desired 'look and feel' of the Moodle site.

- Following the start-up meeting, an initial staff development session was arranged with the nominated school Moodle administrator and champion. During this session, staff were introduced to the basic administrative tasks required to manage Moodle.

- Once the design of the Moodle had been finalized and the basics training had taken place, further sessions were arranged focusing on the pedagogical use of Moodle as identified by each school in discussions with the staff development officer. It was felt that for the project to be successful, staff development should be relevant to the needs and priorities of the school and should also take place at the school, in an environment that staff would be familiar with and at times to suit the school. This had the additional advantage that the staff development officer was able to identify issues in situ thereby rectifiying them more readily.

\section{Evaluation}

In order to undertake an evaluation of the project, each of the Moodle environments was reviewed to gain an impression of how the schools are using Moodle. A questionnaire was also circulated to all schools in the Local Authority to establish the length of time they had been using Moodle, how it is being used and promoted, their approach to training and the extent to which they were using technology more generally. Of the 140 schools in RCT, responses were received from 29 schools, including 1 Special School, 4 secondary schools and the remainder primary or infants. Only 3 of the respondents were schools that were not using Moodle. A more detailed analysis of Moodle use by the respondents' schools was then undertaken to identify the range of activities being adopted.

\subsection{Findings}

An initial overview of Moodle use by schools shows that Moodle is used primarily as a repository for curriculum content, a website and as a means of providing information to parents/carers and the school community.

More detailed analysis, based on the questionnaire and the type of activities used in each Moodle instance reveals a wider range of more interactive tools in some cases. More notably, it becomes apparent that there is a distinct relationship between the role of the headteacher and senior management and the extent to which Moodle is used. The analysis also illustrates the importance of a varied approach to staff development and the need for a whole school approach. Of particular interest are the significant differences between the use of 
Moodle by primary schools and secondary schools. In secondary schools, Moodle is generally viewed as a website and as a repository for resources and/or management information. One school also uses Moodle as an effective means of communicating between teachers, pupils and parents. There is limited evidence of some of the more interactive tools being used. One the other hand, while many primary schools use Moodle primarily as a website, there are a number of examples where Moodle is used more innovatively, using a range of the different interactive activities and tools available.

\subsection{Examples}

Secondary school A: use focuses on Moodle as a means of communication with parents and teachers; some subject areas also use Moodle as a repository for resources, including past exam papers, practice material and weblinks; there is little evidence of more interactive tools being used. Staff development is provided in-house and although the school had previous experience of using a VLE and started using Moodle in 2008, there has been little change with the school confirming that 'Use of Moodle seems to have remained constant and remained in the areas highlighted'

Secondary school B: recent changes in the Senior Management team at the school have led to more widespread use of Moodle in the school and the adoption of a variety of activities including questionnaires and quizzes. The school has also introduced the concept of 'digital leaders' to lead on and promote the use of Moodle in each subject area; staff development has taken place in a variety of formats, including in-house, with support from the University's Moodle team, one-to-one and groupbased.

Primary school A: a whole school approach has been adopted and the use of Moodle is promoted in a variety of different ways, ranging from a means of communication with parents and governors, to a tool for supporting school planning and sharing good practice and showing pupils' work. Pupils are encouraged to use the environment through the adoption of 'Moodle Doodler of the week'; staff development is on-going and takes place in a variety of formats.

Primary school B: Moodle is not promoted and staff find it easier to use the school blog. Staff development has been limited to basic training.

Primary school C: Moodle is not promoted as a whole school initiative and it is managed by just one member of staff; staff development happens in house but this has not been effective; staff are left 'to use it as they wish'.

\section{Conclusions}

Although the response rate to the questionnaire was low, about 20\%, the information provided illustrates that there seems to be a direct correlation between the way in which a school adopts Moodle and the role of senior management in promoting its use. Equally significant seem to be the time and importance given to an appropriate model for staff development. Where Moodle is used most extensively and for a range of activities, the headteacher and senior management teams have adopted a clear strategy to promote its use; staff development takes a range of formats and pupils are encouraged to interact and even take the lead in some cases. Where Moodle remains undeveloped in a school, staff development has often been ad-hoc and there is little incentive for teachers to use it through a whole-school approach.

This paper has focused on looking at the background to the project and identifying how Moodle is being used. It also raises questions in a number of areas for further research, most notably, the role of staff development in developing the use of VLEs in schools and the relationship between leadership and the effective use of VLEs. It will also be important to evaluate the impact of Moodle on learning and teaching and outcomes.

\section{References}

[1] Becta (2008) Self-Review Framework [Accessed 30/10/12 from http://webarchive.nationalarchives.gov.uk/200712041 30131/schools.becta.org.uk/index.php?section=srf ]

[2] Department for Education \& Skills (2005) Harnessing Technology: Transforming learning and children's services [Accessed 15/01/12 from http://tna.europarchive.org/20070402111851/http://w ww.dfes.gov.uk/publications/e-strategy/docs/estrategy.pdf ]

[3] Department of Education, Northern Ireland (2005) [Accessed 15/01/12 from http://www.deni.gov.uk/index/85schools/15_ict_in_schools.htm]

[4] Education Scotland (2012) [Accessed 15/01/12 from http://www.ltscotland.org.uk/usingglowandict/glow/in dex.asp]

[5] Ertmer, P \& Ottenbreit-Leftwich (2010), Teacher Technology Change: How Knowledge, Confidence, Beliefs, and Culture Intersect, Journal of Research on Technology in Education, vol 42, 3, pp 255-284.

[6] Hall, G.E. (2010), Technology's Achilles Heel: Achieving High-Quality Implementation, Journal of Research on Technology in Education, Vol 42, 3, pp 231-253 
[7] Luckin, $\mathrm{R}$ et al (2006), Initiating e-learning by stealth, participation and consultation in a late majority institution, Journal of Organisational Transformation and Social Change, vol 3, 3, pp317 332.

[8] Martin, G, Massey, J \& Clarke, T (2003) When absorptive capacity meets institutions and (e)learners: adopting, diffusing and exploiting $e$ learning in organizations, International Journal of Training and Development, Vol 7, 4, pp228 - 244.

[9] Means, B (2010), Technology and Education Change: Focus on Student Learning, Journal of Research on Technology in Education, Vol 42, 3, pp 285-307

[10] National Assembly for Wales (2003) Community Focused Schools [Accessed 06/01/12 from $\mathrm{http} / / /$ wales.gov.uk/dcells/publications/publications/ci rcularsindex/03/communityfocusedschools/nafwc340 $3-$ e.pdf;jsessionid=4SQ2PGyL141j4ZvjvGTvcJDTw6vr jtt8wmzVJYgnWFnc2bYPkLSh!1090709019?lang=e $\mathrm{n}$ ]

[11] Northern Ireland Education \& Training Inspectorate (2008), An Evaluation of the Use and Impact of Learning Environments in Schools and in the Wider Education Service

[12] Ofsted (2009), Virtual Learning Environments: an evaluation of their development in a sample of educational settings [Accessed 10/08/12 from http://www.ofsted.gov.uk/resources/virtual-learningenvironments-evaluation-of-their-developmentsample-of-educational-settings ]

[13] Strudler, N (2010), Perspectives on Technology and Educational Change, Journal of Research on Technology in Education, Vol 42, 3, pp221-229.

[14] Welsh Assembly Government (2008a) School Effectiveness Framework [Accessed 06/01/12 from http://wales.gov.uk/topics/educationandskills/publicat ions/guidance/schooleffectivenessframework/?lang=e n ]

[15] Welsh Assembly Government (2008b) Transforming Schools with ICT: The Report to the Welsh Assembly Government of the Schools ICT Strategy Working Group [Accessed 06/01/12 from http://www.ngflcymru.org.uk/ictstrategyworkinggroup-e.pdf ]

[16] Welsh Government (2010a) Delivering a Digital Wales [Accessed 06/07/11 from http://wales.gov.uk/docs/det/publications/101208digit alwalesen.pdf ]

[17] Welsh Government (2010b) Learning Pathways, Wider Choice and Flexibility, [Accessed 15/01/12 from

http://wales.gov.uk/topics/educationandskills/pathway s/choice/;jsessionid=6gqLPSncfJyXgrJQP8LrG1HM BR8m15vylPGnxsM6vTklhfPTjxH1!1534110569?la $\mathrm{ng}=\mathrm{en}$ ]
[18] Welsh Government (2012), Find it, make it, use it, share it: learning in digital Wales, [Accessed 24/10/12 from http://wales.gov.uk/docs/dcells/publications/120328di gitalen.pdf ] 